\title{
Non-enzymatic Amperometric Glucose Sensor Based on Copper Nanowires Decorated Reduced Graphene Oxide
}

\author{
Lele $\mathrm{Ju},{ }^{[a]}$ Guosong $\mathrm{Wu},{ }^{[\mathrm{a}]}$ Biao Lu, ${ }^{[\mathrm{a}]}$ Xiaoyun $\mathrm{Li},{ }^{[\mathrm{a}]}$ Huaping $\mathrm{Wu},{ }^{[\mathrm{b}]}$ and Aiping Liu ${ }^{*[\mathrm{a}, \mathrm{c}]}$
}

\begin{abstract}
A nanocomposite consisting of one-dimensional copper nanowires and two-dimensional reduced graphene oxide nanosheets (CuNWs/rGO) was synthesized by a simple one-step wet-chemical synthetic process. The $\mathrm{Cu}$ NWs anchored onto the rGO nanosheets with wrinkles and folds had a smooth surface. The CuNWs/rGO hybrids exhibited excellent electrocatalytic activity toward glucose oxidation due to the superior conductivity along one-dimensional direction and excellent catalytic activity of $\mathrm{Cu}$ NWs and rapid electron transfer in the two-dimensional rGO sheets. A wide linear range up to $11 \mathrm{mM}$, high sensitivity $\left(1625 \mu \mathrm{A} /\left(\mathrm{mM} \cdot \mathrm{cm}^{2}\right)\right)$, low detection limit
\end{abstract}

$(0.2 \mu \mathrm{M})$ and fast response $(<2 \mathrm{~s})$ to glucose oxidation were obtained under a working potential of $0.58 \mathrm{~V}$ for the hybrid with optimized $\mathrm{Cu} / \mathrm{rGO}$ mass ratio in the alkaline solution. Furthermore, the $\mathrm{CuNWs} / \mathrm{rGO}$ composites displayed high selectivity to glucose and resistance against poisoning by commonly interfering species such as ascorbic acid, dopamine, uric acid, acetamidophenol and some carbohydrates. The CuNWs/rGO hybrids with good reproducibility, stability and poisoning resistance to chloride ions were therefore promising for the potential application as non-enzymatic amperometric glucose sensors with improved electrochemical performances.

Keywords: Copper nanowire $\cdot$ Reduced graphene oxide $\cdot$ Hydrothermal synthesis $\cdot$ Non-enzymatic glucose sensor $\cdot$ Electrocatalytic activity

\section{Introduction}

Glucose, existing widely in blood of living beings, can be directly involved in the metabolic process in human body. The development of rapid, simple, sensitive and reliable methods for accurate glucose detection is important in many areas such as biotechnology, food industry, chemistry and environmental protection $[1,2]$. Due to the high sensitivity, simplicity and short response time, the electrochemical sensor is regarded as one of the most popular and effective methods for detecting glucose by the direct catalytic oxidation of glucose [3,4]. The first-generation glucose sensors based on enzymes have many drawbacks such as the intrinsic instability of enzymes, complexity and high cost [5-7]. By contrast, the low-cost, non-enzymatic glucose sensors are stable, highly sensitive with a low detection limit, and are therefore concerned greatly. Noble metal nanostructures such as gold, platinum, and palladium have been used as catalysts for constructing non-enzymatic glucose sensors. However, the expensive price of noble metals makes them difficult to a wide range of commercial application. Moreover, chloride ion, abundant existence in human blood, can poison the electrode materials, resulting in the loss of their activity [3]. In order to retain excellent catalytic activity and low-cost production, more attention has been focused on the $\mathrm{Cu}$ based materials [7-31]. In recent years, various $\mathrm{Cu}$-based nanostructures, such as monometallic and bimetal nanoparticles and nanorods [2,7-15,21-25], polyhedrons [26] and nanowires [28-31], have been synthesized for construction of non-enzymatic glucose sensors. These $\mathrm{Cu}-$ based materials not only show superior electrical conduc- tivity but also resistant against a poison by chloride ion in the solution $[7,21,24]$. Particularly, the $\mathrm{Cu}$ nanowires $(\mathrm{Cu}$ NWs) as one-dimensional nanomaterials have been reported to be highly sensitive to glucose oxidation due to their excellent electron transfer along one-dimensional direction [32]. However, the single $\mathrm{Cu}$ NWs are instable and easy to oxidize with long-term use. Therefore, a catalyst support should be considered for use to improve the durability of catalysts [7,12,15,17-25,33].

The graphene (GE) or reduced graphene oxide ( $\mathrm{rGO}$ ) with high electrical conductivity, large specific surface area, distinguished mechanical properties and strong adhesion ability for metal catalyst is believed as an excellent catalyst support to improve activity and durability of catalysts [34]. Up to now, some studies based on the $\mathrm{Cu} / \mathrm{GE}$ or $\mathrm{Cu} / \mathrm{rGO}$ nanocomposite materials for glucose detection have been carried out. For example, Luo et al. adopted an electrochemically deposited method to synthesize $\mathrm{Cu}$ nanoparticles on the GE sheets modified glassy carbon electrode for glucose detection [27]. Fan et al. fab-

[a] L. Ju, G. Wu, B. Lu, X. Li, A. Liu

Center for Optoelectronics Materials and Devices, Zhejiang Sci-Tech University, Hangzhou 310018, China

*e-mail: liuaiping1979@gmail.com

[b] H. Wu

Key Laboratory of E\&M (Zhejiang University of Technology), Ministry of Education \& Zhejiang Province, Hangzhou 310014, China

[c] A. Liu

State Key Laboratory of Nonlinear Mechanics, Institute of Mechanics, Chinese Academy of Sciences, Beijing 100190, China 
ricated $\mathrm{Cu}$ NWs modified GE transparent electrode through spin-coating $\mathrm{Cu}$ NWs onto GE surface and confirmed the excellent catalytic activity for glucose oxidation [31]. However, most researches related to CuNWbased catalysts for glucose sensing usually adopt a twostep synthesis procedure, namely CuNWs preparation and CuNW-catalyst support recombination, which is complicated and time-consuming. Additionally, the protection role of $\mathrm{GE}$ or $\mathrm{rGO}$ to the $\mathrm{Cu}$ NWs from oxidation is not well investigated.

In this work, we fabricate $\mathrm{CuNWs} / \mathrm{rGO}$ hybrids through a facile, one-step wet-chemical synthetic approach. The effect of rGO content on the structures, catalytic performance and long-term stability of CuNWs/rGO hybrids is carefully investigated by changing the quality ratio of $\mathrm{GO}$ to $\mathrm{Cu}$-based precursor. The $\mathrm{CuNWs} / \mathrm{rGO}$ hybrid displays fascinating sensitivity, fast amperometric response, excellent selectivity and wide detection range for glucose oxidation due to the superior conductivity along one-dimensional direction and excellent catalytic activity of $\mathrm{Cu}$ NWs and rapid electron transfer in the two-dimensional rGO sheets. The synergistic effect of $\mathrm{Cu}$ NWs and rGO favors the hybrids significant electrocatalytic activity toward glucose oxidation when compared to the single rGO or $\mathrm{Cu}$ NWs. The good reproducibility and long-term stability of the hybrids are contributed to the protection role of $\mathrm{rGO}$ to the $\mathrm{Cu}$ NWs.

\section{Experimental}

\subsection{Materials}

Sodium hydroxide $(\mathrm{NaOH})$, copper nitrate $\left(\mathrm{Cu}\left(\mathrm{NO}_{3}\right)_{2} \cdot 3 \mathrm{H}_{2} \mathrm{O}\right)$, ethylenediamine (EDA), hydrazine $\left(\mathrm{N}_{2} \mathrm{H}_{4} 35 \mathrm{wt} \%\right)$, potassium ferricyanide $\left(\mathrm{K}_{3}\left[\mathrm{Fe}(\mathrm{CN})_{6}\right]\right)$, potassium chloride $(\mathrm{KCl})$, dopamine $(\mathrm{DA})$, ascorbic acid (AA), uric acid (UA), acetamidophenol (AP), fructose, sucrose and Nafion were purchased from Sigma-Aldrich. Other reagents were commercially available and of analytical reagent grade. Graphite powder (256 mesh) was supplied by Qingdao Huatai Tech. Co. Ltd. Deionized water with resistance of approximately $18 \mathrm{M} \Omega \cdot \mathrm{cm}$ was used throughout the experiment.

\subsection{Preparation of Cu NWs and CuNWs/rGO Hybrids}

The GO was prepared from natural graphite powder by using modified Hummers' method [35]. Cu NWs were synthesized by using the modified method reported in the previous work [36]. Typically, $20 \mathrm{~mL}$ of concentraed $\mathrm{NaOH}$ solution $(15 \mathrm{M})$ in a flask was pre-heated to $60^{\circ} \mathrm{C}$, followed by dropwise addition of $1 \mathrm{~mL} \mathrm{Cu}\left(\mathrm{NO}_{3}\right)_{2}$ solution $(0.1 \mathrm{M})$. The resulting solution was stirred for $15 \mathrm{~min}$ and then $0.16 \mathrm{~mL}$ EDA and $25 \mu \mathrm{L} \mathrm{N} \mathrm{N}_{2} \mathrm{H}_{4}$ solution (35 wt \%) were injected into the flask. The flask was capped and maintained at $60^{\circ} \mathrm{C}$ for $1.5 \mathrm{~h}$, followed by cooling down to room temperature in an ice bath. The reddish production was filtered and washed with excessive ice water. Fi- nally, the as-prepared $\mathrm{Cu}$ NWs were dried in a vacuum oven.

In a typical process of $\mathrm{CuNWs} / \mathrm{rGO}$ synthesis, a $9 \mathrm{mg}$ $\mathrm{GO}$ powder was dispersed in $3 \mathrm{~mL}$ deionized water. Then the suspension $(3 \mathrm{mg} / \mathrm{mL})$ was sonicated for $1 \mathrm{~h}$ in order to disperse the $\mathrm{GO}$ uniformly. $\mathrm{A} \mathrm{Cu}\left(\mathrm{NO}_{3}\right)_{2}$ solution $(1 \mathrm{~mL}, 0.1 \mathrm{M})$ in a glass vial was mixed with different amounts of GO, namely $0.107 \mathrm{~mL}, \quad 0.213 \mathrm{~mL}$ and $0.427 \mathrm{~mL}$ (corresponding to the quality ratio of $\mathrm{GO}$ to $\mathrm{Cu}$ of $0.05,0.1$ and 0.2 ), respectively, and the obtained three vials were labeled as $\mathrm{S}_{1}, \mathrm{~S}_{2}$ and $\mathrm{S}_{3}$, respectively. After adding $0.16 \mathrm{~mL}$ EDA, the color of solutions changed from blue to dark violet with sequentially sonicated for $10 \mathrm{~min}$ again. Then the dark violet solutions were dropwise added into pre-heated $\mathrm{NaOH}(20 \mathrm{~mL}, 15 \mathrm{M})$ at $60^{\circ}$ Cwith stirring. After that, $35 \mu \mathrm{L}, 45 \mu \mathrm{L}$ and $65 \mu \mathrm{L}$ $\mathrm{N}_{2} \mathrm{H}_{4}$ solution (35 wt.\%) were injected into the $\mathrm{S}_{1}, \mathrm{~S}_{2}$ and $\mathrm{S}_{3}$ flasks, respectively, and the three flasks were capped and maintained at $60^{\circ} \mathrm{C}$ for $1.5 \mathrm{~h}$ without stirring, followed by cooling down to room temperature. The productions were washed and collected by centrifugation in deionized water and ethanol in order to remove the excess alkali and unreacted reagents, respectively.

For electrode preparation, the ITO-coated glasses were sonicated in ethanol and deionized water for $10 \mathrm{~min}$, respectively, and dried in $\mathrm{N}_{2} .3 \mathrm{mg} \mathrm{CuNWs} / \mathrm{rGO}$ hybrid was mixed with $1 \mathrm{~mL}$ ethanol and $20 \mu \mathrm{L}$ Nafion solution ( $5 \mathrm{wt} \%$ in ethanol), and then the dispersion was ultrasonically treated to form the ink (catalyst dispersion). After that, $20 \mu \mathrm{L}$ ink was dropped onto the ITO electrode with the average apparent area $0.4 \mathrm{~cm}^{2}(0.8 \mathrm{~cm} \times 0.5 \mathrm{~cm})$ and subsequently dried under vacuum for $2 \mathrm{~h}$ at room temperature. The $\mathrm{Cu}$ NWs or rGO modified electrodes as comparison were also prepared in a similar way.

\subsection{Characterization and Measurements}

The morphologies of different hybrids were observed by a Field emission scanning electron microscope (FESEM, Hitachi S4800). The X-ray diffraction (XRD) pattern was obtained on a diffractometer (Bruker AXS D8) using the $\mathrm{Cu}$ Ka radiation $(\lambda=0.15418 \mathrm{~nm})$ with the $2 \theta$ scan from $10^{\circ}$ to $80^{\circ}$ at a step of $0.02^{\circ}$. The Raman spectra of GO and $\mathrm{CuNWs} / \mathrm{rGO}$ on silica wafers were collected by a Thermo Fisher DXR Raman spectrometer with a HeNe laser $(\lambda=632.8 \mathrm{~nm})$. The Fourier transform infrared (FTIR) spectra of GO and CuNWs/rGO were recorded using a Bruker Tensor 27 spectrometer with samples embedded in KBr disks. The XPS core level spectra and elemental composition of different samples were collected by the X-ray photoelectron spectroscopy (XPS, KRATOS AXIS ULTRA-DLD) with the binding energies calibrated by $\mathrm{C} 1 \mathrm{~s}$ as reference energy $(\mathrm{C} 1 \mathrm{~s}=284.6 \mathrm{eV})$. The electrochemical measurements were carried out with a CHI660B electrochemical workstation (Shanghai Chenhua Instrument Factory, China) in a three-electrode cell, which consisted of a working electrode, a platinum wire as the counter electrode, and $\mathrm{Ag} / \mathrm{AgCl}(3 \mathrm{M} \mathrm{KCl})$ elec- 


\section{Full Paper}

trode as the reference electrode, respectively. The behavior of glucose oxidation on the working electrode was investigated by cyclic voltammetry $(\mathrm{CV})$ at a potential range from $0.1 \mathrm{~V}$ to $0.8 \mathrm{~V}$, chronoamperometry (I-T) and electrochemical impedance spectroscopy (EIS) technique. The supporting electrolyte in CV and I-T experiments was $0.1 \mathrm{M} \mathrm{NaOH}$ solution with nitrogen saturated. All currents obtained on the electrodes were normalized to the apparent area of each electrode with same catalyst loading.

\section{Results and Discussion}

\subsection{Microstructures of $\mathrm{Cu}$ NWs and CuNWs/rGO Hybrids}

During the preparation process of $\mathrm{Cu}$ NWs and CuNWs/ rGO hybrids, the EDA is necessary as the structure-directing agent to promote the anisotropic growth of $\mathrm{Cu}$ NWs from copper spherical seeds which were reduced from copper complexes of $\mathrm{Cu}(\mathrm{OH})_{4}{ }^{2-}$ by $\mathrm{N}_{2} \mathrm{H}_{4}$ in the high concentrated alkaline solution [36]. Fig. 1 displays typical SEM images of GO nanosheet, $\mathrm{Cu}$ NWs and CuNWs/rGO composites. The GO nanosheets have some
Table 1. Element contents of different catalysts obtained from XPS measurement.

\begin{tabular}{lccc}
\hline \multirow{2}{*}{ Catalyst } & \multicolumn{3}{l}{ Element content (wt.\%) } \\
\cline { 2 - 4 } & $\mathrm{C}$ & $\mathrm{O}$ & $\mathrm{Cu}$ \\
\hline rGO & 64.6 & 35.4 & - \\
$\mathrm{Cu} \mathrm{NWs}$ & - & 3.8 & 96.2 \\
CuNWs/rGO $\left(\mathrm{S}_{1}\right)$ & 30.7 & 16.7 & 52.6 \\
CuNWs/rGO $\left(\mathrm{S}_{2}\right)$ & 34.8 & 19.2 & 46.0 \\
CuNWs/rGO $\left(\mathrm{S}_{3}\right)$ & 41.5 & 23.1 & 35.4 \\
\hline
\end{tabular}

wrinkles and folds on the surfaces and edges (Fig. 1a). The $\mathrm{Cu}$ NWs are uniform with an average diameter of $100 \mathrm{~nm}$ and the length from dozen to dozens of micrometer (Figs. 1b). As shown in the high-magnification SEM image (Fig. 1c), the surface of 100-nm-diameter $\mathrm{Cu}$ NWs is smooth. For the $\mathrm{CuNWs} / \mathrm{rGO}$ hybrids, the $\mathrm{Cu}$ NWs are anchored onto the rGO nanosheets. With the increase of GO amount, the $\mathrm{Cu}$ NWs on the rGO sheet become loose and the connection degree among these $\mathrm{Cu}$ NWs is weakened (Figs. 1d-f). Table 1 displays the element contents of different catalysts. The content ratio of carbon element to the oxygen one $(\mathrm{C}: \mathrm{O})$ is about $1.8 \pm 0.1$ for the three CuNWs/rGO catalysts, which is similar to the value

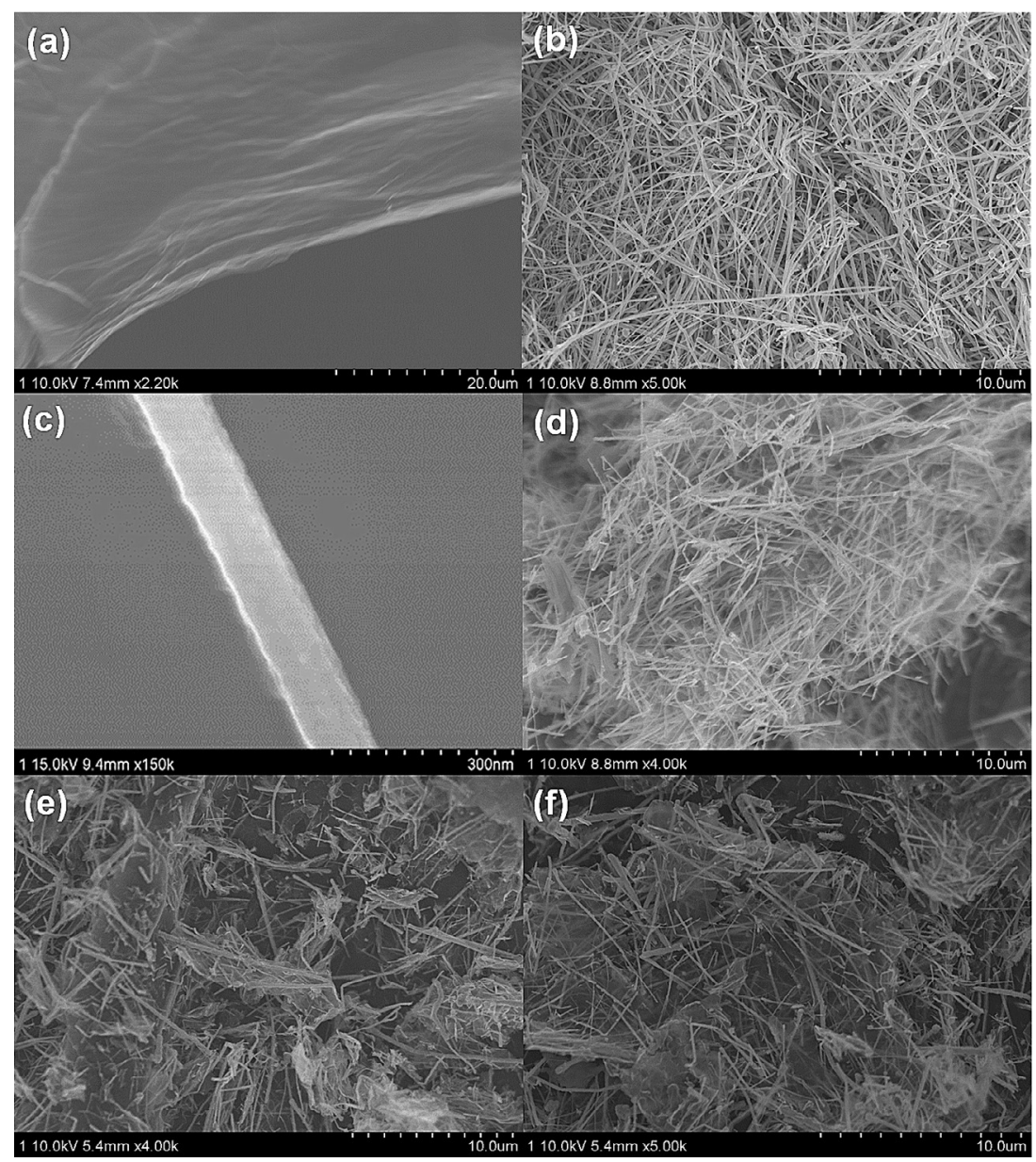

Fig. 1. Scanning electron microscopy images of (a) GO sheets, (b)-(c) Cu NWs, and (d)-(f) CuNWs/rGO composites based on $\mathrm{S}_{1}$, $\mathrm{S}_{2}$ and $\mathrm{S}_{3}$, respectively. 

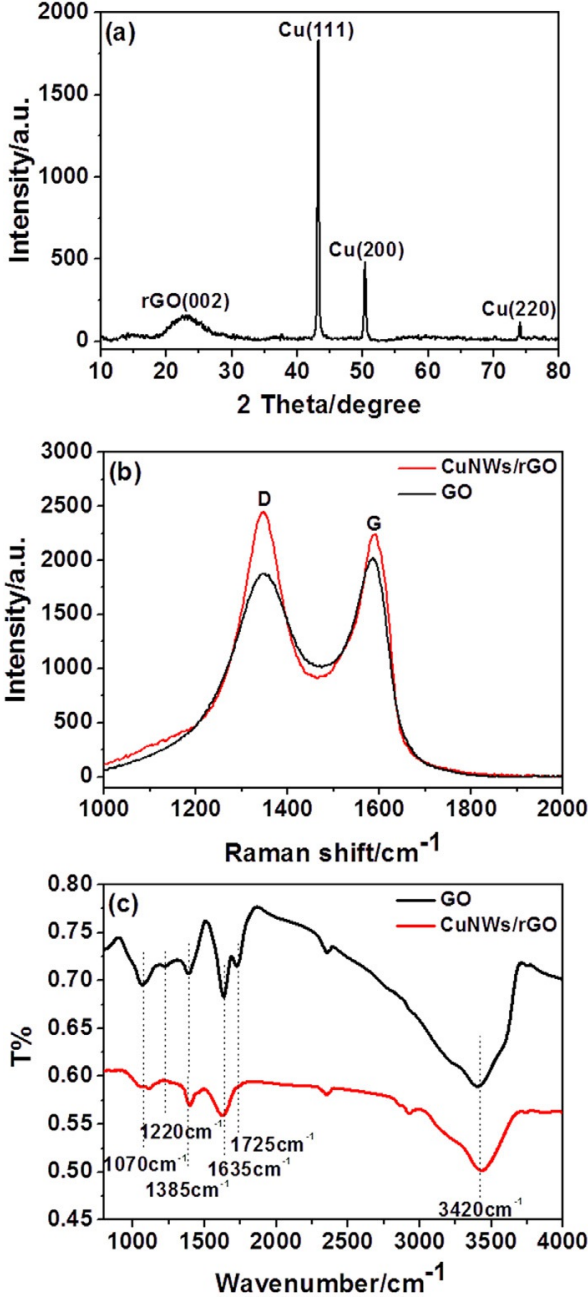

Fig. 2. (a) XRD pattern of CuNWs/rGO $\left(\mathrm{S}_{2}\right)$ composites, (b) Raman spectra and (c) FTIR spectra of GO and CuNWs/rGO $\left(\mathrm{S}_{2}\right)$ composites.

of pure rGO. This hints that the incorporation of $\mathrm{Cu}$ NWs in the rGO does not introduce extra oxygen component. Therefore, the $\mathrm{Cu}$ NWs obtained in our synthesis is neat and the oxygen signal observed in the $\mathrm{Cu}$ NWs catalyst might be attributed to the oxygen absorbed on the $\mathrm{Cu}$ NWs.

Fig. 2(a) shows the XRD pattern of CuNWs/rGO $\left(\mathrm{S}_{2}\right)$ composites. The broad characteristic peak at $23.1^{\circ}$ indicates the successful reduction of $\mathrm{GO}$ to $\mathrm{rGO}$ with poor ordering along its stacking direction [37]. The diffraction peaks located at $43.3^{\circ}, 50.4^{\circ}$ and $74.1^{\circ}$ perfectly match the (1 1 1), (2 00 ) and (311) crystalline planes of $\mathrm{Cu}$ with face-centered cubic crystal structure (JCPDS 04-0836), respectively. The absence of the diffraction peaks of $\mathrm{CuO}$ and $\mathrm{Cu}_{2} \mathrm{O}$ implies the pure $\mathrm{Cu} N W s$ in production. From the Raman spectra of $\mathrm{GO}$ and $\mathrm{CuNWs} / \mathrm{rGO}\left(\mathrm{S}_{2}\right)$ composites shown in Fig. 2(b), the GO and rGO display two prominent peaks at $1345 \mathrm{~cm}^{-1}$ and $1588 \mathrm{~cm}^{-1}$, corresponding to the D-bands (arising from the tangential stretch of $\mathrm{sp}^{2}$-hybridized carbon) and the G-bands (representing the crystalline graphite with $\mathrm{E}_{2 \mathrm{~g}}$ zone center mode), respec- tively [38]. The intensity ratios of D-band to G-band ( $\mathrm{I}_{\mathrm{D}} /$ $\mathrm{I}_{\mathrm{G}}$ ) increase from 0.93 for $\mathrm{GO}$ to 1.10 for $\mathrm{CuNWs} / \mathrm{rGO}$, suggesting more defects introduced into rGO. From the FTIR of GO in Fig. 2(c), three characteristic peaks at $1070 \mathrm{~cm}^{-1}\left(v_{\mathrm{C}-\mathrm{O}}\right), 1635 \mathrm{~cm}^{-1}\left(v_{\mathrm{C}=\mathrm{C}}\right)$ and $1725 \mathrm{~cm}^{-1}\left(v_{\mathrm{C}=\mathrm{O}}\right)$ reveal the existence of oxygen-containing functional groups in the GO. However, the peaks $\left(v_{\mathrm{C}=\mathrm{O}}\right.$ and $\left.v_{\mathrm{C}-\mathrm{O}}\right)$ disappear or are weakened in the FTIR of CuNWs/rGO $\left(\mathrm{S}_{2}\right)$, implying the amount of oxygen-containing functional groups is remarkably less after GO reduction by hydrazine.

EIS is a useful tool to study characteristic of electrode related to electron transfers between the electrolyte and the electrode surface. It is proposed that the semicircle diameter at higher frequencies reflects the electron-transfer resistance [39]. Fig. 3 shows the EIS results in Nyquist plots for bare ITO, ITO-Nafion, ITO-Nafion-rGO, ITONafion-CuNWs and ITO-Nafion-CuNWs/rGO $\left(\mathrm{S}_{2}\right)$ electrodes, and the corresponding equivalent circuit model. The $R_{S}$ is defined as the series resistance of the system and represents the ohmic resistance of electrolyte between the electrode and Luggin capillary and that within the pores of the catalysts. The $\mathrm{R}_{\mathrm{CT}}$ is the charge transfer resistance between the solid-liquid interface. Our simulated results show that the values of $\mathrm{R}_{\mathrm{CT}}$ for different electrodes increase in the order of bare ITO $(4 \Omega)<$ ITONafion-CuNWs/rGO $\quad(6 \Omega)<$ ITO-Nafion-CuNWs $(13 \Omega)<$ ITO-Nafion-rGO $(24 \Omega)<$ ITO-Nafion $(34 \Omega)$. After modifying ITO electrode with Nafion, the $R_{C T}$
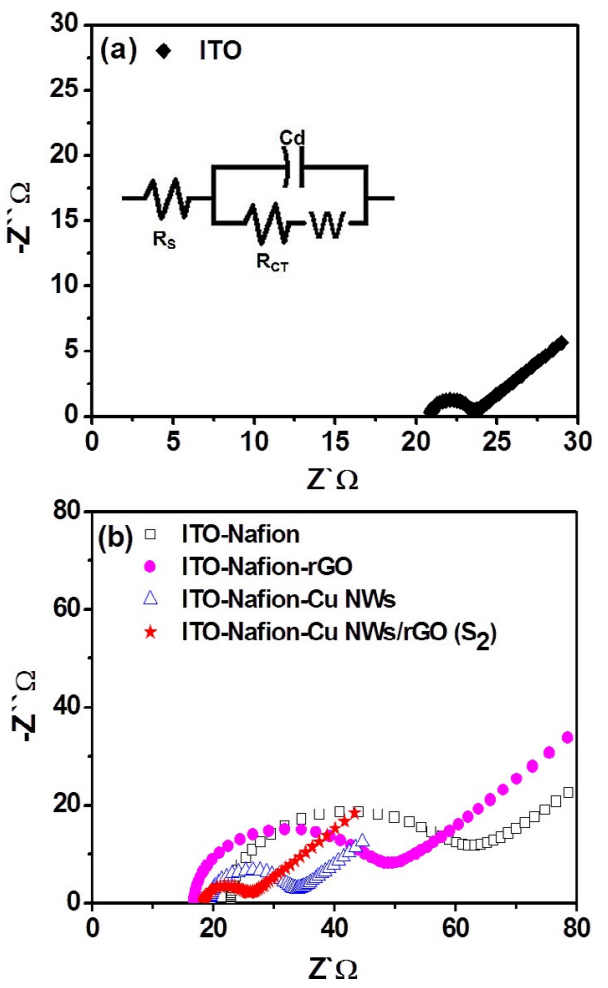

Fig. 3. Electrochemical impedance spectra of (a) ITO glass and (b) different electrodes in the $0.1 \mathrm{M} \mathrm{KCl}$ electrolyte solution containing $0.01 \mathrm{M} \mathrm{Fe}(\mathrm{CN})_{6}^{3-/ 4-}$. 
value increases remarkably owing to the Nafion hindering in the interfacial charge transfer. The ITO-Nafion-rGO and ITO-Nafion-CuNWs electrodes have lower resistances when compared to the ITO-Nafion electrodes due to the good conductivity of rGO and $\mathrm{Cu}$ NWs. The CuNWs/ rGO $\left(\mathrm{S}_{2}\right)$ composites exhibit smaller semicircle diameter at high frequencies and lower electron-transfer resistance due to the synergistic effect of one-dimensional $\mathrm{Cu}$ NWs and two-dimensional rGO sheets.

\subsection{Electrochemical Activities of CuNWs/rGO Hybrids}

The electrocatalytic activities of $\mathrm{rGO}, \mathrm{Cu} \mathrm{NWs}$ and CuNWs/rGO composites are investigated in $0.1 \mathrm{M} \mathrm{N}_{2}$-saturated $\mathrm{NaOH}$ solution with and without $2 \mathrm{mM}$ glucose at a scan rate of $50 \mathrm{mV} / \mathrm{s}$. No current related to glucose oxidation can be found on rGO modified electrode (Fig. 4a). For the $\mathrm{Cu}$ NWs modified electrode, the background current increases with the potential scanning towards positive direction. When $2 \mathrm{mM}$ glucose is added to the reaction system, an apparent shoulder peak at about $0.55 \mathrm{~V}$ with a rapid increase in current is observed, which corresponds to the oxidation of glucose (Fig. 4a). The possible oxidation mechanism of glucose at $\mathrm{Cu}$-modified electrode in the alkaline media is proposed by the following steps $[31,40]$ :

$$
\begin{aligned}
& \mathrm{Cu}+2 \mathrm{OH}^{-} \rightarrow \mathrm{CuO}+\mathrm{H}_{2} \mathrm{O}+2 \mathrm{e}^{-}, \\
& \mathrm{CuO}+\mathrm{OH}^{-} \rightarrow \mathrm{CuOOH}+\mathrm{e}^{-} \\
& \text {or } \mathrm{CuO}+\mathrm{H}_{2} \mathrm{O}+2 \mathrm{OH}^{-} \rightarrow \mathrm{Cu}(\mathrm{OH})_{4}^{-}+\mathrm{e}^{-}, \\
& \mathrm{Cu}(\mathrm{III})+\text { glucose }+\mathrm{e}^{-} \rightarrow \\
& \text { gluconolactone }+\mathrm{Cu}(\mathrm{II}), \\
& \text { gluconolactone }+\mathrm{Cu}(\mathrm{II}) \rightarrow \\
& \text { gluconic acid (hydrolysis })+\mathrm{Cu}(\mathrm{II}) .
\end{aligned}
$$

The $\mathrm{Cu}(0)$ is electrochemically oxidated to $\mathrm{Cu}(\mathrm{II})$ species through the transition of $\mathrm{Cu}(0) / \mathrm{Cu}$ (II) at the negative potential [41] and further oxidated to $\mathrm{Cu}$ (III) species such as $\mathrm{CuOOH}$ or $\mathrm{Cu}(\mathrm{OH})_{4<\text { brtr- }}$ at about $0.55 \mathrm{~V}$, which are considered as the strong oxidizing agent for glucose oxidation. Moreover, the $\mathrm{Cu}(\mathrm{III})$ species are consumed in the electrooxidation of glucose as confirmed by the absence of peak related to the transition of $\mathrm{Cu}(\mathrm{III}) / \mathrm{Cu}$ (II) in the cathodic scan (Fig. 4a). Therefore, rGO has no contribution to direct nonenzymatic glucose detection while $\mathrm{Cu}$ NWs play a primary role in the electroxidation process of glucose. For CuNWs/rGO hybrids with different amounts of rGO, a rapid increase in current starting at $0.3 \mathrm{~V}$ with an obvious oxidation peak generated at around $0.58 \mathrm{~V}$ is collected due to the glucose oxidation (Fig. 4b) when the $2 \mathrm{mM}$ glucose is added into the system. In contrast to the $\mathrm{Cu}$ NWs, the CuNWs/rGO hybrids exhibit higher current response relative to own background current, indicating a stronger electrocatalytic
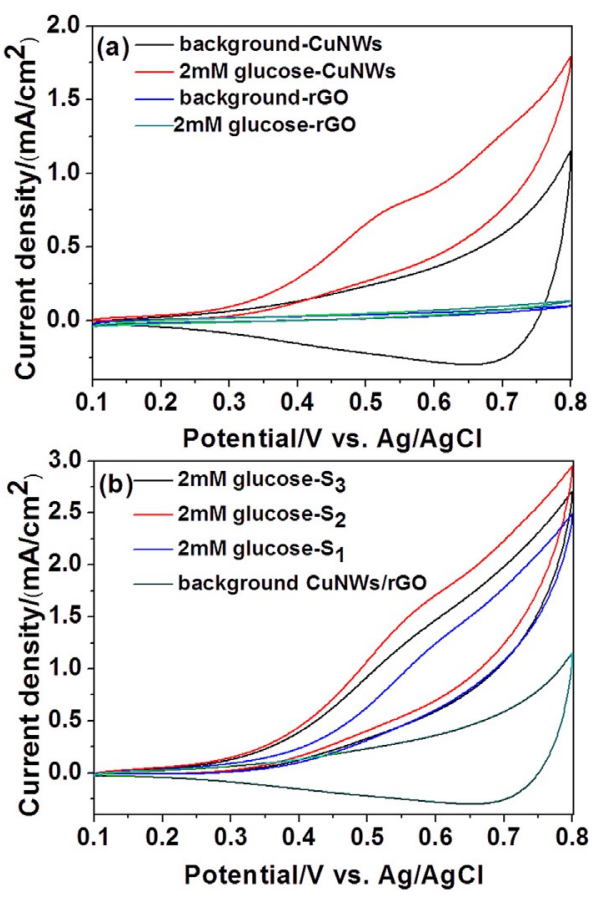

Fig. 4. (a) Cyclic voltammograms of $\mathrm{Cu} \mathrm{NWs}$ and rGO modified electrodes in $0.1 \mathrm{M} \mathrm{N}_{2}$-saturated $\mathrm{NaOH}$ with and without $2 \mathrm{mM}$ glucose, respectively. (b) Cyclic voltammograms of CuNWs/rGO composites $\left(\mathrm{S}_{1}, \mathrm{~S}_{2}\right.$ and $\left.\mathrm{S}_{3}\right)$ modified electrodes in $0.1 \mathrm{M} \mathrm{N}_{2}$-saturated $\mathrm{NaOH}$ with and without $2 \mathrm{mM}$ glucose, respectively.

capacity toward the oxidation of glucose. The remarkable electrocatalytic activity of CuNWs/rGO hybrids may originate from the superior conductivity along one-dimensional direction and excellent catalytic activity of $\mathrm{Cu}$ NWs and rapid electron transfer in the two-dimensional rGO sheets. It is worth noting that the current response of CuNWs/rGO hybrids modified electrodes based on $\mathrm{S}_{1}$ and $S_{3}$ are lower than that based on $S_{2}$. This means that a suitable amount of GO not only guarantees the tight junctions between $\mathrm{Cu}$ NWs but also exposes sufficient $\mathrm{Cu}$ active sites for glucose oxidation.

The electrochemically effective surface area of CuNWs/rGO modified electrode has been calculated according to the method provided by Liu et al. [42]. First, the effective surface areas of the bare ITO and $\mathrm{rGO} / \mathrm{ITO}$ electrodes are estimated to be 0.234 and $0.490 \mathrm{~cm}^{2}$, respectively, by using $\mathrm{K}_{3}\left[\mathrm{Fe}(\mathrm{CN})_{6}\right]$ as a model complex (Fig. 5) according to the general Randles-Sevcik equation [43]. Since the CuNWs in the CuNWs/rGO composite would react with $\mathrm{K}_{3}\left[\mathrm{Fe}(\mathrm{CN})_{6}\right]$, the effective surface area of CuNWs/rGO electrode can be calculated according to the relation of electrical double layer capacitance with effective surface area based on cyclic voltammetry measurements (Fig. 6) [44]. Our calculated results reveal that the CuNWs/rGO modified electrodes based on $\mathrm{S}_{1}, \mathrm{~S}_{2}$ and $\mathrm{S}_{3}$ have larger effective surface areas $(1.518,1.719$ and $1.617 \mathrm{~cm}^{2}$, respectively) than ITO and $\mathrm{rGO} / \mathrm{ITO}$ ones, which further contribute to their good electrochemical activities for glucose detection. 

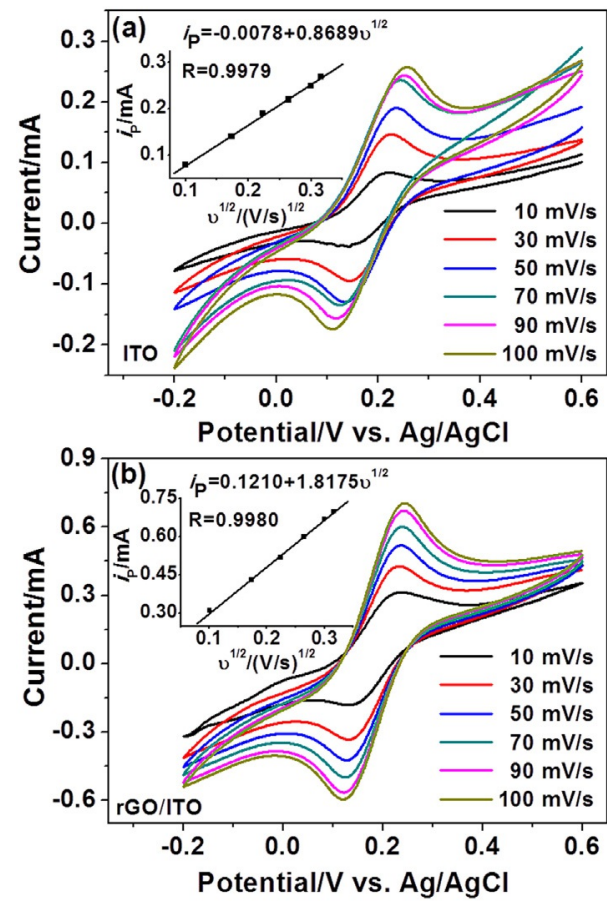

Fig. 5. Cyclic voltammograms of (a) ITO and (b) rGO/ITO electrodes in $0.1 \mathrm{M} \mathrm{KCl}$ containing $5 \mathrm{mM} \mathrm{K}_{3}\left[\mathrm{Fe}(\mathrm{CN})_{6}\right]$ at different scan rates $(v)$. Insets are the relations of anodic $i_{\mathrm{P}}$ versus $v^{1 / 2}$.

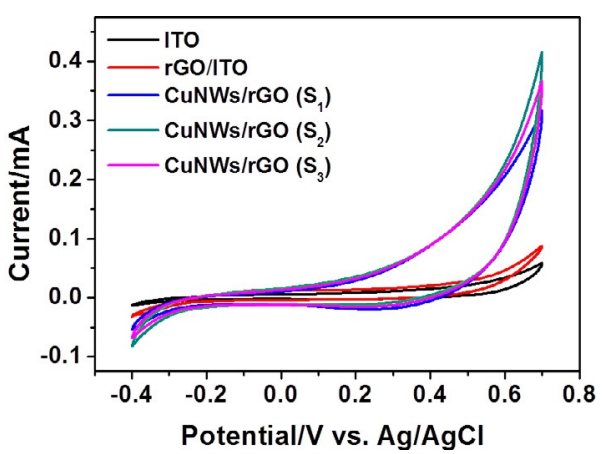

Fig. 6. Cyclic voltammograms for different electrodes in $0.1 \mathrm{M}$ $\mathrm{NaOH}$ at a scan rate of $0.1 \mathrm{~V} / \mathrm{s}$.

It is generally known that the working potential affects the amperometric response of sensors. Therefore, we explore the effect of working potential on the electrochemical behaviors of $\mathrm{CuNW} / \mathrm{rGO}\left(\mathrm{S}_{2}\right)$ composites modified electrodes with successive addition of $0.1 \mathrm{mM}$ glucose in the $0.1 \mathrm{M} \mathrm{N}_{2}$-saturated $\mathrm{NaOH}$ solution at $50 \mathrm{~s}$ interval. As shown in Fig. 7, the maximum step-like current response is observed at $0.58 \mathrm{~V}$. For the working potential higher or lower than $0.58 \mathrm{~V}$, the oxidative current response is lower. Moreover, a higher potential may favor the oxidation of intermediate interferents. Hence, the optimal working potential is $0.58 \mathrm{~V}$ for $\mathrm{CuNWs} / \mathrm{rGO}$ catalysts.

Fig. 8 shows the current-time (I-T) curves of CuNWs/ rGO composites modified electrodes based on $\mathrm{S}_{1}, \mathrm{~S}_{2}$ and

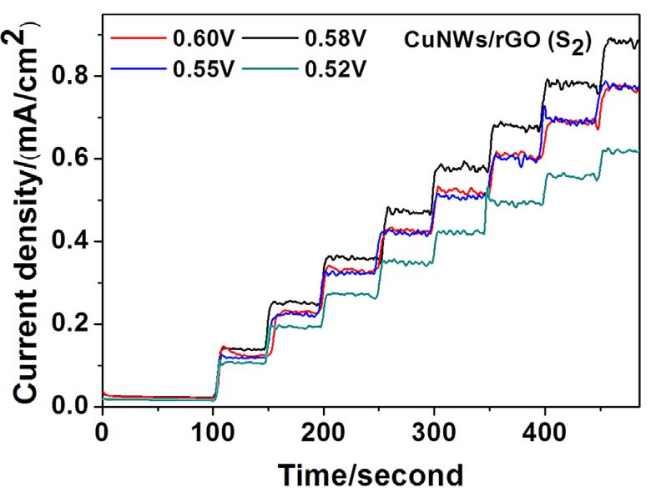

Fig. 7. Amperometric responses of CuNWs/rGO $\left(\mathrm{S}_{2}\right)$ composites modified electrodes at different potentials with successive addition of $0.1 \mathrm{mM}$ glucose in the $0.1 \mathrm{M} \mathrm{N}_{2}$-saturated $\mathrm{NaOH}$ solution at $50 \mathrm{~s}$ interval.

$\mathrm{S}_{3}$ samples by successive injection of glucose solution into the $0.1 \mathrm{M} \mathrm{N}_{2}$-saturated $\mathrm{NaOH}$ solution at $0.58 \mathrm{~V}$, and the corresponding calibration plots are displayed in Fig. 8(c) and Fig. 8(f), respectively. As successive injection of glucose, the CuNWs/rGO composites modified electrodes present large step-like increase of current density, which reaches the steady-state equilibrium within $2 \mathrm{~s}$, indicating an attractive short response time. This might result from the superior conductivity along one-dimensional direction of $\mathrm{Cu}$ NWs and rapid electron transfer in the two-dimensional rGO sheets. Moreover, compared to the I-T curves of $S_{1}$ and $S_{3}$, the current density of glucose oxidation obtained from $\mathrm{S}_{2}$ is higher obviously and the detection range for glucose concentration is wider. The corresponding sensitivity, correlation coefficient, linear response range, and detection limit $(\mathrm{S} / \mathrm{N}=3)$ are summarized in Table 2. One can see that the CuNWs/rGO composites modified electrode based on $\mathrm{S}_{2}$ has the highest sensitivity $\left(1625 \mu \mathrm{A} /\left(\mathrm{mM} \cdot \mathrm{cm}^{2}\right)\right)$, the lowest detection limit $(0.2 \mu \mathrm{M})$ and the widest detection range $(1 \mu \mathrm{M}-11 \mathrm{mM})$ to glucose oxidation since a small amount of GO can not guarantee the close interlinking between $\mathrm{Cu}$ NWs and $\mathrm{rGO}$, while a large amount of GO may impede the transport of glucose molecules to the active sites on the $\mathrm{Cu}$ NWs. A performance comparison of the $\mathrm{CuNWs} / \mathrm{rGO}$ composites modified electrodes based on $\mathrm{S}_{2}$ with those of reported non-enzymatic glucose sensors is shown in Table 3 . It is clear that our sensor based on the CuNWs/rGO hybrids exhibits exciting characteristics of high sensitivity, low detection limit and wide response range and therefore is

Table 2. Sensor properties of different CuNWs/rGO composites modified electrodes.

\begin{tabular}{lllll}
\hline $\begin{array}{l}\text { Catalyst } \\
\text { sponse range } \\
\text { sinear re- }\end{array}$ & $\begin{array}{l}\text { Sensitivity }(\mu \mathrm{A} / \\
\left.\left(\mathrm{mM} \cdot \mathrm{cm}^{2}\right)\right)\end{array}$ & $\begin{array}{l}\text { Detection } \\
\text { limit }(\mu \mathrm{M})\end{array}$ & $\mathrm{R}^{2}$ \\
\hline $\mathrm{S}_{1}$ & $5 \mu \mathrm{M}-9 \mathrm{mM}$ & 600 & 1.6 & 0.988 \\
$\mathrm{~S}_{2}$ & $1 \mu \mathrm{M}-11 \mathrm{mM}$ & 1625 & 0.2 & 0.993 \\
$\mathrm{~S}_{3}$ & $5 \mu \mathrm{M}-9 \mathrm{mM}$ & 1075 & 0.6 & 0.990 \\
\hline
\end{tabular}



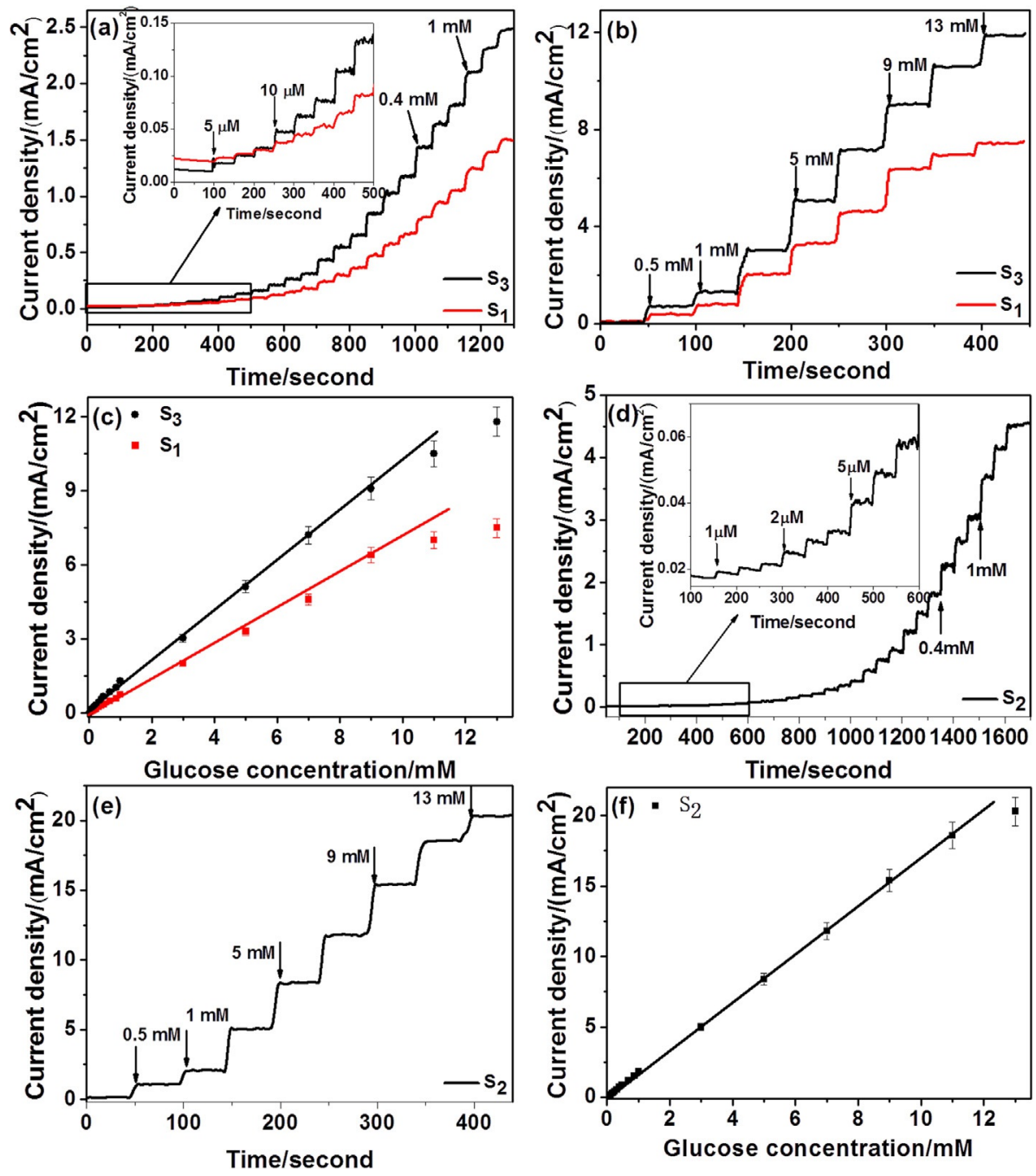

Fig. 8. (a)-(b) Amperometric responses of CuNWs/rGO composites modified electrodes based on $\mathrm{S}_{1}$ and $\mathrm{S}_{3}$ for successive addition of various-concentration glucose in the $0.1 \mathrm{M} \mathrm{N}_{2}$-saturated $\mathrm{NaOH}$ solution at $0.58 \mathrm{~V}$. (c) Corresponding calibration curves of (a) and (b). (d)-(e) Amperometric response of CuNWs/rGO composites modified electrode based on $\mathrm{S}_{2}$ for successive addition of variousconcentration glucose in the $0.1 \mathrm{M} \mathrm{N}_{2}$-saturated $\mathrm{NaOH}$ solution at $0.58 \mathrm{~V}$. (f) Corresponding calibration curve of (d) and (e). The insets in (a) and (d) are amplified I-T curves. Error bars in (c) and (f) indicate the relative standard deviations of six measurements. The line indicates the calibration curve.

promising for the determination of blood sugar concentration in the practical clinical analysis.

\subsection{Reproducibility, Stability and Anti-interference Property of CuNWs/rGO Based Sensor}

The reproducibility of the developed sensor is evaluated by measuring the current response of five $\mathrm{CuNWs} / \mathrm{rGO}$ composite modified electrodes upon $0.1 \mathrm{mM}$ glucose in $0.1 \mathrm{M} \mathrm{N}_{2}$-saturated $\mathrm{NaOH}$ solution with a relative standard deviation (RSD) of $4.3 \%$. Meanwhile ten successive addition of $0.1 \mathrm{mM}$ glucose is measured for the same electrode with the RSD of $2.1 \%$. These results indicate that the CuNWs/rGO composite based sensor has a good reproducibility. The stability and antioxidant capacity of the developed sensor is investigated by measuring the current response to glucose oxidation $(1 \mathrm{mM})$ and ele- ment contents after three months. It can be seen that the current response obtained from CuNWs/rGO $\left(\mathrm{S}_{2}\right)$ decreases by $8 \%$ and $17 \%$ after ten days and three months, respectively, when compared to the initial current. While the current response obtained from $\mathrm{Cu}$ NWs decreases by $15 \%$ and $36 \%$ at the same time interval when compared to the initial current (Fig. 9). The RSD up to $4.0 \%$ is calculated based on six measurements at the different catalysts modified electrode. Furthermore, the mass ratio of $\mathrm{Cu} / \mathrm{O}$ displays a significant decrease with time lengthening for the $\mathrm{Cu}$ NWs catalyst after exposed to ambient condition when compared to that of the $\mathrm{CuNWs} / \mathrm{rGO}$ $\left(\mathrm{S}_{2}\right)$. This implies that the rGO layer could effectively protect the $\mathrm{Cu} \mathrm{NWs}$ from oxidation during a long-term employment.

Additionally, many interfering species such as AA, DA, UA, AP and some carbohydrates (fructose and sucrose) 
Table 3. Performance comparison of various non-enzymatic glucose sensors.

\begin{tabular}{|c|c|c|c|c|c|}
\hline Electrode & Working potential (V) & Linear response range & Sensitivity & Detection limit $(\mu \mathrm{M})$ & Reference \\
\hline $\mathrm{Cu} \mathrm{NWs/rGO}$ & 0.58 & $1 \mu \mathrm{M}-11 \mathrm{mM}$ & $1625 \mu \mathrm{AmM}^{-1} \mathrm{~cm}^{-2}$ & 0.2 & this work \\
\hline $\mathrm{Cu}$ NWs/GTE & 0.6 & $5 \mu \mathrm{M}-6 \mathrm{mM}$ & $1100 \mu \mathrm{AmM}^{-1} \mathrm{~cm}^{-2}$ & 1.6 & [31] \\
\hline $\mathrm{Cu}$ NWs/MWCNTS & 0.55 & $1 \mu \mathrm{M}-3 \mathrm{mM}$ & $1995 \mu \mathrm{AmM}^{-1} \mathrm{~cm}^{-2}$ & 0.26 & {$[30]$} \\
\hline $\mathrm{Cu}$ NWs & 0.6 & $0.1 \mu \mathrm{M}-3 \mathrm{mM}$ & $420.3 \mu \mathrm{AmM}^{-1} \mathrm{~cm}^{-2}$ & 0.035 & {$[28]$} \\
\hline $\mathrm{Cu}$ NPs/graphene & 0.5 & $4 \mu \mathrm{M}-4.5 \mathrm{mM}$ & $48.13 \mu \mathrm{AmM}^{-1}$ & 1.3 & {$[24]$} \\
\hline $\mathrm{Cu}$ nanocubes/MWCNTS & 0.55 & $3 \mu \mathrm{M}-7.5 \mathrm{mM}$ & $1096 \mathrm{uAmM}^{-1} \mathrm{~cm}^{-2}$ & $\begin{array}{l}1.3 \\
1\end{array}$ & {$[45]$} \\
\hline Cu@C NWs & 0.65 & $0.05 \mathrm{M}-3 \mathrm{mM}$ & $437.8 \mu \mathrm{AmM}^{-1} \mathrm{~cm}^{-2}$ & 0.05 & {$[46]$} \\
\hline $\mathrm{Cu}$ nanoclusters & 0.65 & $1 \mu \mathrm{M}-5 \mathrm{mM}$ & $17.76 \mu \mathrm{AmM}^{-1}$ & 0.5 & {$[47]$} \\
\hline $\mathrm{CuO}$ NPs/GO & 0.7 & $2.79 \mu \mathrm{M}-2.03 \mathrm{mM}$ & $262.5 \mu \mathrm{AmM}^{-1} \mathrm{~cm}^{-2}$ & 0.69 & {$[39]$} \\
\hline $\mathrm{Cu}_{2} \mathrm{O}$ nanocunes/graphene & 0.6 & $0.3 \mathrm{mM}-3.3 \mathrm{mM}$ & $285 \mu \mathrm{AmM}^{-1} \mathrm{~cm}^{-2}$ & 3.3 & {$[48]$} \\
\hline
\end{tabular}

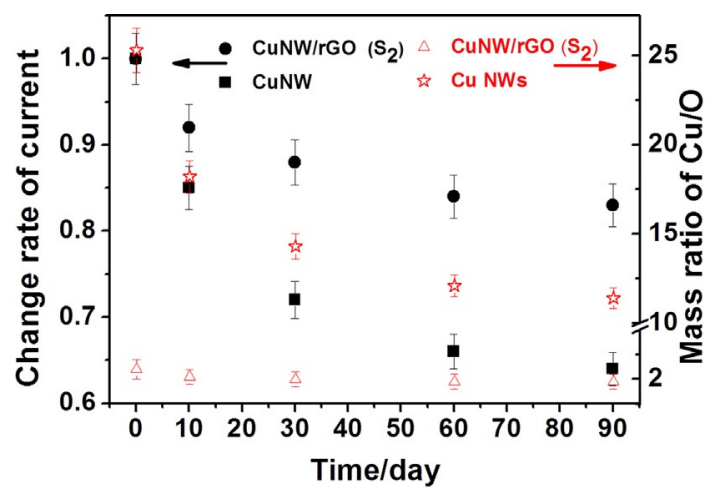

Fig. 9. Dependences of change rate of current related to glucose oxidation $(1 \mathrm{mM})$ and mass ratio of $\mathrm{Cu} / \mathrm{O}$ of different catalysts on exposure time. Error bars indicate the relative standard deviations calculated based on six measurements at the $\mathrm{Cu} N W s$ and $\mathrm{CuNWs} / \mathrm{rGO}(\mathrm{S} 2)$ catalysts modified electrode.

coexist with glucose in real physiological samples. Therefore, the anti-interference property is an important factor for biosensors. The interference experiment of CuNWs/ rGO $\left(\mathrm{S}_{2}\right)$ composite based sensor is executed by the addition of $0.5 \mathrm{mM}$ glucose and $0.5 \mathrm{mM}$ AA, UA, DA, AP, fructose and sucrose, respectively, as shown in Fig. 10. The current response produced by the oxidation of interfering species does not show any significant effect to the glucose oxidation after the second addition of glucose, suggesting the high specificity to glucose detection using $\mathrm{CuNWs} / \mathrm{rGO}$ hybrids. When the $0.1 \mathrm{M} \mathrm{KCl}$ solution is added in the $\mathrm{NaOH}$ solution, only $5-8 \%$ reduce in current can be detected, indicating the good poisoning resistance of the catalyst to the environment containing chloride ions, as reported by previous studies [7,24].

The analysis capability of the developed sensor for the real sample is investigated by adding $20.0 \mu \mathrm{L}$ of human serum sample obtained from a local hospital in the $5.0 \mathrm{~mL}$ of $0.1 \mathrm{M} \mathrm{N}_{2}$-saturated $\mathrm{NaOH}$ solution. The current response for glucose at $0.58 \mathrm{~V}$ is determined by the RSD of pure glucose to the solutions containing the serum samples, and the RSD recorded by the injections of $0.5 \mathrm{mM}$ glucose in five solutions is calculated to be about $4.1 \%$. Our results show that this glucose biosensor based on $\mathrm{CuNW} / \mathrm{rGO}$ hybrids is suitable for the determination of real serum samples.
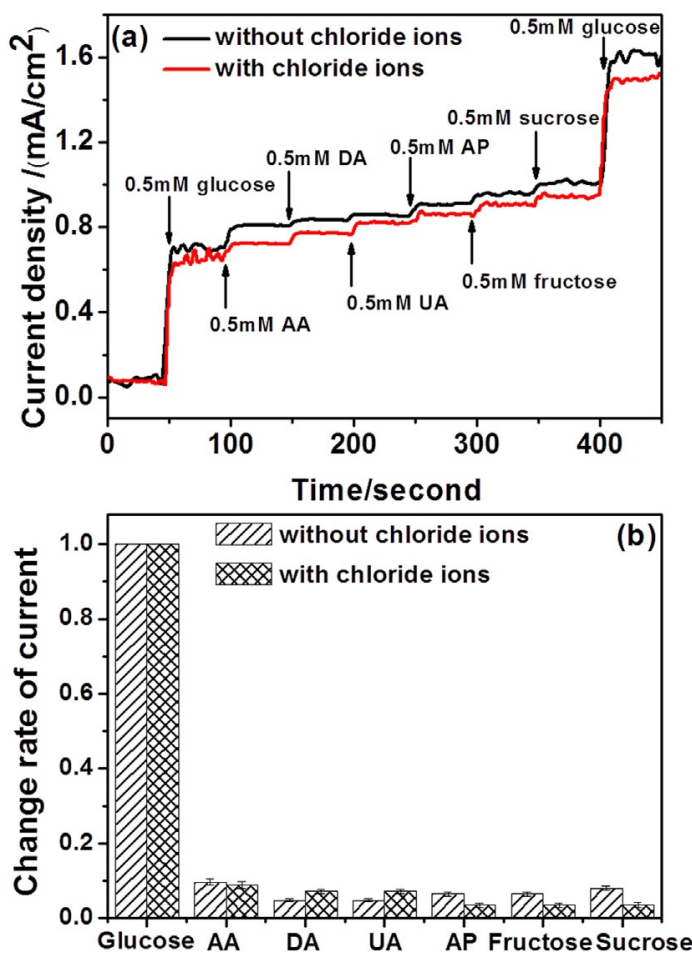

Fig. 10. (a) Interference test of CuNWs/GO $\left(\mathrm{S}_{2}\right)$ composite modified electrodes in the $0.1 \mathrm{M} \mathrm{N}_{2}$-saturated $\mathrm{NaOH}$ solution with and without chloride ions at $0.58 \mathrm{~V}$ with the addition of $0.5 \mathrm{mM}$ glucose, $0.5 \mathrm{mM}$ ascorbic acid (AA), $0.5 \mathrm{mM}$ dopamine (DA), $0.5 \mathrm{mM}$ uric acid (UA), $0.5 \mathrm{mM}$ acetamidophenol (AP), $0.5 \mathrm{mM}$ fructose and $0.5 \mathrm{mM}$ sucrose. (b) Current rate of current of interferences related to glucose oxidation. Error bars indicate the relative standard deviations calculated based on six measurements.

\section{Conclusions}

A series of $\mathrm{CuNW} / \mathrm{rGO}$ composites were fabricated by a one-step wet chemical approach for the exploitation of non-enzymatic glucose sensors. The content of rGO in CuNWs/rGO composites had great impact on the performance of non-enzymatic glucose sensors. The CuNWs/ rGO composite electrode with optimized $\mathrm{Cu} / \mathrm{rGO}$ mass ratio displayed wide linear range $(1 \mu \mathrm{M}-11 \mathrm{mM})$, high sensitivity $\left(1625 \mu \mathrm{A} /\left(\mathrm{mM} \cdot \mathrm{cm}^{2}\right)\right.$, low detection limit $(0.2 \mu \mathrm{M})$, fast response $(<2 \mathrm{~s})$, satisfactory reproducibility 
and good selectivity for glucose oxidation in the alkaline solution even containing chloride ions. The simple and low-cost synthesis procedure of $\mathrm{CuNWs} / \mathrm{rGO}$ hybrid and its excellent properties make it potential application for non-enzymatic amperometric glucose sensors.

\section{Acknowledgements}

This work was supported by the National Natural Science Foundation of China (Grant Nos. 51272237, 51572242 and 11372280), the Zhejiang Provincial Natural Science Foundation of China (Grant No. LY16E020011), the 521 Talent Project of Zhejiang Sci-Tech University and the Program for Innovative Research Team of Zhejiang SciTech University, the Opening Fund of State Key Laboratory of Nonlinear Mechanics and the Program for Innovative Research Team of Zhejiang Sci-Tech University (Grant No. 15010039-Y).

\section{References}

[1] N. Mitro, P. A. Mak, L. Vargas, C. Godio, E. Hampton, V. Molteni, A. Kreusch, E. Saez, Nature 2007, 445, 219-223.

[2] Q. Chen, L. Zhang, G. Chen, Anal. Chem. 2011, 84, 171178.

[3] J. Wang, Chem. Rev. 2008, 108, 814-825.

[4] X.-C. Dong, H. Xu, X.-W. Wang, Y.-X. Huang, M. B. ChanPark, H. Zhang, L.-H. Wang, W. Huang, P. Chen, ACS nano 2012, 6, 3206-3213.

[5] P. Si, Y. Huang, T. Wang, J. Ma, RSC Adv. 2013, 3, $3487-$ 3502.

[6] X.-M. Chen, Z.-J. Lin, D.-J. Chen, T.-T. Jia, Z.-M. Cai, X.R. Wang, X. Chen, G.-N. Chen, M. Oyama, Biosens. Bioelectron. 2010, 25, 1803-1808.

[7] M. Yuan, A. Liu, M. Zhao, W. Dong, T. Zhao, J. Wang, W. Tang, Sens. Actuators B 2014, 190, 707-714.

[8] L. Chen, T. Fujita, Y. Ding, M. Chen, Adv. Funct. Mater. 2010, 20, 2279-2285.

[9] H. Li, C.-Y. Guo, C.-L. Xu, Biosens. Bioelectron. 2015, 63, $339-346$.

[10] S. Xu, H. Li, L. Wang, Q. Yue, S. Sixiu, J. Liu, CrystEngComm 2014, 16, 9075-9082.

[11] M.-M. Guo, P.-S. Wang, C.-H. Zhou, Y. Xia, W. Huang, Z. Li, Sens. Actuators B 2014, 203, 388-395.

[12] M. Y. Elahi, A. Khodadadi, Y. Mortazavi, J. Electrochem. Soc. 2014, 161, B81-B87.

[13] X. Zhang, Q. Liao, S. Liu, W. Xu, Y. Liu, Y. Zhang, Anal. Chim. Acta, 2015, 858, 49-54.

[14] X. Zhang, R. Ji, L. Wang, L. Yu, J. Wang, B. Geng, G. Wang, CrystEngComm 2013, 15, 1173-1178.

[15] L. Wang, Y. Zheng, X. Lu, Z. Li, L. Sun, Y. Song, Sens. Actuators $B$ 2014, 195, 1-7.

[16] F. Sun, L. Li, P. Liu, Y. Lian, Electroanalysis 2011, 23, 395401.

[17] C.-L. Sun, W.-L. Cheng, T.-K. Hsu, C.-W. Chang, J.-L. Chang, J.-M. Zen, Electrochem. Commun. 2013, 30, 91-94.

[18] N. Q. Dung, D. Patil, H. Jung, D. Kim, Biosens. Bioelectron. 2013, 42, 280-286.

[19] Y.-W. Hsu, T.-K. Hsu, C.-L. Sun, Y.-T. Nien, N.-W. Pu, M.D. Ger, Electrochim. Acta 2012, 82, 152-157.
[20] X. Zhou, H. Nie, Z. Yao, Y. Dong, Z. Yang, S. Huang, Sens. Actuators B 2012, 168, 1-7.

[21] Y. Tian, Y. Liu, W.-P. Wang, X. Zhang, W. Peng, Electrochim. Acta 2015, 156, 244-251.

[22] Y. Zhao, X. Bo, L. Guo, Electrochim. Acta 2015, 176, 12721279.

[23] Q. Wang, Q. Wang, M. Li, S. Szunerits, R. Boukherroub, RSC Adv. 2015, 5, 15861-15869.

[24] D. Jiang, Q. Liu, K. Wang, J. Qian, X. Dong, Z. Yang, X. Du, B. Qiu, Biosens. Bioelectron. 2014, 54, 273-278.

[25] L.-M. Lu, X.-B. Zhang, G.-L. Shen, R.-Q. Yu, Anal. Chim. Acta 2012, 715, 99-104.

[26] L. Xu, J. Xia, H. Li, H. Li, K. Wang, S. Yin, Eur. J. Inorg. Chem. 2011, 9, 1361-1365.

[27] J. Luo, S. Jiang, H. Zhang, J. Jiang, X. Liu, Anal. Chim. Acta 2012, 709, 47-53.

[28] Y. Zhang, L. Su, D. Manuzzi, H. V. E. de los Monteros, W. Jia, D. Huo, C. Hou, Y. Lei, Biosens. Bioelectron. 2012, 31, $426-432$

[29] J. Bao, C. Hou, Y. Zhang, Q. Li, D. Huo, M. Yang, X. Luo, J. Electrochem. Soc. 2015, 162, B47-B51.

[30] J. Huang, Z. Dong, Y. Li, J. Li, J. Wang, H. Yang, S. Li, S. Guo, J. Jin, R. Li, Sens. Actuators B 2013, 182, 618-624.

[31] Z. Fan, B. Liu, X. Liu, Z. Li, H. Wang, S. Yang, J. Wang, Electrochim. Acta 2013, 109, 602-608.

[32] M. Mohl, P. Pusztai, A. Kukovecz, Z. Konya, J. Kukkola, K. Kordas, R. Vajtai, P. M. Ajayan, Langmuir 2010, 26, $16496-$ 16502.

[33] A. P. Periasamy, J. Liu, H.-M. Lin, H.-T. Chang, J. Mater. Chem. A 2013, 1, 5973-5981.

[34] Y. Liu, X. Dong, P. Chen, Chem. Soc. Rev. 2012, 41, 22832307.

[35] C. Chen, Q.-H. Yang, Y. Yang, W. Lv, Y. Wen, P.-X. Hou, M. Wang, H.-M. Cheng, Adv. Mater. 2009, 21, 3007-3011.

[36] A. R. Rathmell, S. M. Bergin, Y. L. Hua, Z. Y. Li, B. J. Wiley, Adv. Mater. 2010, 22, 3558-3563.

[37] Y. Xu, K. Sheng, C. Li, G. Shi, ACS nano 2010, 4, 43244330.

[38] H. Gao, Y. Wang, F. Xiao, C. B. Ching, H. Duan, J. Phys. Chem. C 2012, 116, 7719-7725.

[39] J. Song, L. Xu, C. Zhou, R. Xing, Q. Dai, D. Liu, H. Song, ACS Appl. Mater. Interfaces, 2013, 5, 12928-12934.

[40] L. Luo, L. Zhu, Z. Wang, Bioelectrochemistry 2012, 88, 156163.

[41] H.-X. Wu, W.-M. Cao, Y. Li, G. Liu, Y. Wen, H.-F. Yang, S.P. Yang, Electrochim. Acta 2010, 55, 3734-3740.

[42] C. B. Liu, H. Zhang, Y. H. Tang, S. L. Luo, J. Mater. Chem. A 2014, 2, 4580-4587.

[43] A. J. Bard, L. R. Faulkner, Electrochemical Methods: Fundamentals and Applications, John Wiley, New York, 2001.

[44] C. H. Xu, B. H. Xu, Y. Gu, Z. G. Xiong, J. Sun, X. S. Zhao, Energy Environ. Sci. 2013, 6, 1388-1414.

[45] J. Yang, W.-D. Zhang, S. Gunasekaran, Biosens. Bioelectron. 2010, 26, 279-284.

[46] Y. Zhao, Z. He, Z. Yan, Analyst 2013, 138, 559-568.

[47] X. Kang, Z. Mai, X. Zou, P. Cai, J. Mo, Anal. Biochem. 2007, 363, 143-150.

[48] M. Liu, R. Liu, W. Chen, Biosens. Bioelectron. 2013, 45, 206-212.

Received: February 18, 2016 Accepted: May 2, 2016 Published online: June 7, 2016 